\title{
PERFIL E PERCEPÇÃO DOS FREQUENTADORES DO PARQUE MUNICIPAL SÃO LOURENÇO DE CURITIBA - PR
}

\author{
PROFILE AND PERCEPTION OF USERS OF SÃO LOURENÇO PARK IN CURITIBA - \\ $B R A Z I L$
}

Maísa Carina Zardin ${ }^{1}$, Jefferson Dias de Oliveira², Juliana Paschoalini Arthuso ${ }^{3}$, Daniela Biondi

\section{RESUMO}

Nos meios urbanos, as áreas verdes urbanas contribuem significativamente para a qualidade de vida e o conhecimento sobre esse assunto é necessário para melhorar a funcionalidade destas áreas. Assim, a percepção ambiental busca caracterizar a participação dos cidadãos na proteção da floresta urbana, e seus conhecimentos e impressões sobre a mesma. Este estudo teve como objetivo investigar a percepção da população em relação ao Parque Municipal São Lourenço de Curitiba - PR. A coleta de dados se deu por meio de questionário semiestruturado com os frequentadores do parque abrangendo três áreas fundamentais: perfil socioeconômico, hábitos de utilização e funções do parque. Foram entrevistadas 128 pessoas, nos dias 12 a 18 de setembro de 2016. O parque é frequentado principalmente por jovens e adultos, e que moram no entorno ou na região do parque. Possui grande frequência de visitação principalmente nos finais de semana e no período da tarde. As atividades de lazer e recreação se configuram como o principal motivo de visitação. Os benefícios gerados à população, como o bem-estar público local, atuam diretamente na melhoria da saúde física e mental dos cidadãos, principalmente por aqueles que somente visitam esse parque, refletindo a importância do Parque São Lourenço para a região.

Palavras-chave: Áreas verdes; Espaços urbanos; Paisagismo; Meio ambiente.

\begin{abstract}
In urban environments, green areas contribute significantly to quality of life and information about the benefits of urban green areas is necessary to improve the functionality of these areas for population. Environmental perception seeks to characterize the participation of citizens in the protection of urban forest, and their knowledge and impressions about it. This study aimed to investigate the perception of users about the São Lourenço Municipal Park, in Curitiba - PR. Data collection was carried out through a semi-structured questionnaire with park visitors, covering three main areas: socioeconomic profile, usage habits and park functions. A total of 128 people were interviewed, from September 12th to 18th, 2016. The park is attended mainly by young people and adults, living around the park or in close neighborhoods. The highest frequency of visitation is on the weekends and in the afternoon. Leisure and recreation activities are the main reason for visitation. The benefits generated to the population, such as local public welfare, act directly to improve physical and mental health of citizens, especially those who have this park as their only choice for interaction with green areas, thus reflecting the importance of São Lourenço Park to its region.
\end{abstract}

Keywords: Green areas; Urban open spaces; Landscape; Environment.

Recebido em 27.06.2017 e aceito em 30.08.2017

1 Engenheira Florestal. Mestranda do Programa de Pós-graduação em Engenharia Florestal da Universidade Federal do Paraná. Curitiba/PR. E-mail: maisazrd@gmail.com

2 Engenheiro Florestal. Mestrando do Programa de Pós-graduação em Engenharia Florestal da Universidade Federal do Paraná. Curitiba/PR. E-mail: jeffddo@gmail.com

3 Engenheira Florestal. Formada pela Universidade de São Paulo. Piracicaba/SP. E-mail: jparthuso@gmail.com

4 Engenheira Florestal. Doutora. Professora Titular da Universidade Federal do Paraná. Curitiba/PR. E-mail: dbiondi@ufpr.br 


\section{INTRODUÇÃO}

Em muitas cidades em desenvolvimento, ocupações urbanas sem planejamento resultam em desigualdade social, e também na chamada "desigualdade espacial", que é caracterizada pelo fato de que apenas parte da população tem acesso a espaços privilegiados, entre eles os espaços verdes (LEICHENKO; SOLECKI, 2008). O aprimoramento destes espaços possibilita meios para melhorar a qualidade de vida da população, mesmo que as cidades sofram rápida urbanização (MITCHELL; POPHAM, 2008).

Herzog e Rosa (2010) evidenciam que espaços verdes urbanos também são responsáveis por serviços ecossistêmicos significativos como purificação do ar e da água, serviços sociais e psicológicos proporcionados pelo contato com o verde, retenção de poluição sonora e estabilização do microclima. Nasir, Ahmad e Ahmed (2016) afirmam que grandes espaços verdes valorizam o ambiente e a estética das cidades, além de constituírem um meio para atividades de comunidade, criando oportunidades de recreação e educação pelo contato com a natureza, mesmo que de forma antropizada. Os mesmos autores proferem que estas áreas também atraem investimentos, turismo e geram empregos, além de oferecer localização ideal para prática de atividades físicas, que contribuem para o aumento da qualidade de vida humana.

Vantajosamente para a área de pesquisas em floresta urbana, um número cada vez maior de artigos tem sido publicado durante a última década lidando com a interação entre os seres humanos e a floresta urbana, sendo que o conhecimento sobre essa interação é necessário para melhorar a funcionalidade de parques e espaços verdes urbanos, em geral (MATSUOKA; KAPLAN, 2008). Dessa forma, o estudo de percepção ambiental busca caracterizar e refletir sobre a participação de cidadãos na conservação da floresta urbana. Apesar do fato de que a maioria da população urbana mundial está nos países em desenvolvimento, as pesquisas, no que diz respeito à percepção ambiental, se concentram nos países desenvolvidos (WILLEMSE, 2012).

De forma complementar, durante estudo entre 1991 e 2006, Matsuoka e Kaplam (2008) encontraram que, dentre 90 artigos analisados sobre percepção de frequentadores da paisagem urbana, $51 \%$ eram da América do Norte, $17 \%$ da Europa e somente 3,3\% da América do Sul. Desta forma, fica clara a necessidade de estudos sobre a percepção da floresta urbana neste último subcontinente.

Portanto, com esta carência de dados e por não abrigar um significativo número de trabalhos referentes à área de percepção, o estudo teve como objetivo investigar a percepção da população em um parque municipal brasileiro, localizado na cidade de Curitiba - PR, o 
Parque São Lourenço, em relação ao perfil socioeconômico dos frequentadores, hábitos de utilização, percepção sobre o paisagismo do parque e suas funções.

\section{MATERIAL E MÉTODOS}

\section{Área de estudo}

A pesquisa foi desenvolvida no Parque Natural Municipal São Lourenço, que foi escolhido por representar importante papel ecológico no município. O parque localiza-se na zona norte do município de Curitiba e possui uma área de $203.918 \mathrm{~m}^{2}$ (20,4 ha) (SILVA et al., 2012), localizado nas coordenadas geográficas de $25^{\circ} 23^{\prime} 01,983^{\prime \prime} S$ e $49^{\circ} 15^{\prime} 58,235^{\prime \prime} \mathrm{W}$, a uma altitude média de $930 \mathrm{~m}$.

O clima é classificado como subtropical úmido, com temperaturas médias de 19,7 ํㅡ no verão e $13,4{ }^{\circ} \mathrm{C}$ no inverno, e devido à sua posição e às suas características topográficas, o verão é ameno e o inverno moderado, com alguns dias mais rigorosos, sendo que a média anual de precipitação é de $1.419,91 \mathrm{~mm}$, com período de estiagem entre o outono e o inverno (BIONDI; MULLER, 2013).

O parque está inserido no Bioma Mata Atlântica, fitofisionomia Floresta Ombrófila Mista, e na bacia hidrográfica do Rio Belém. A localização e contexto regional podem ser observados na Figura 1.

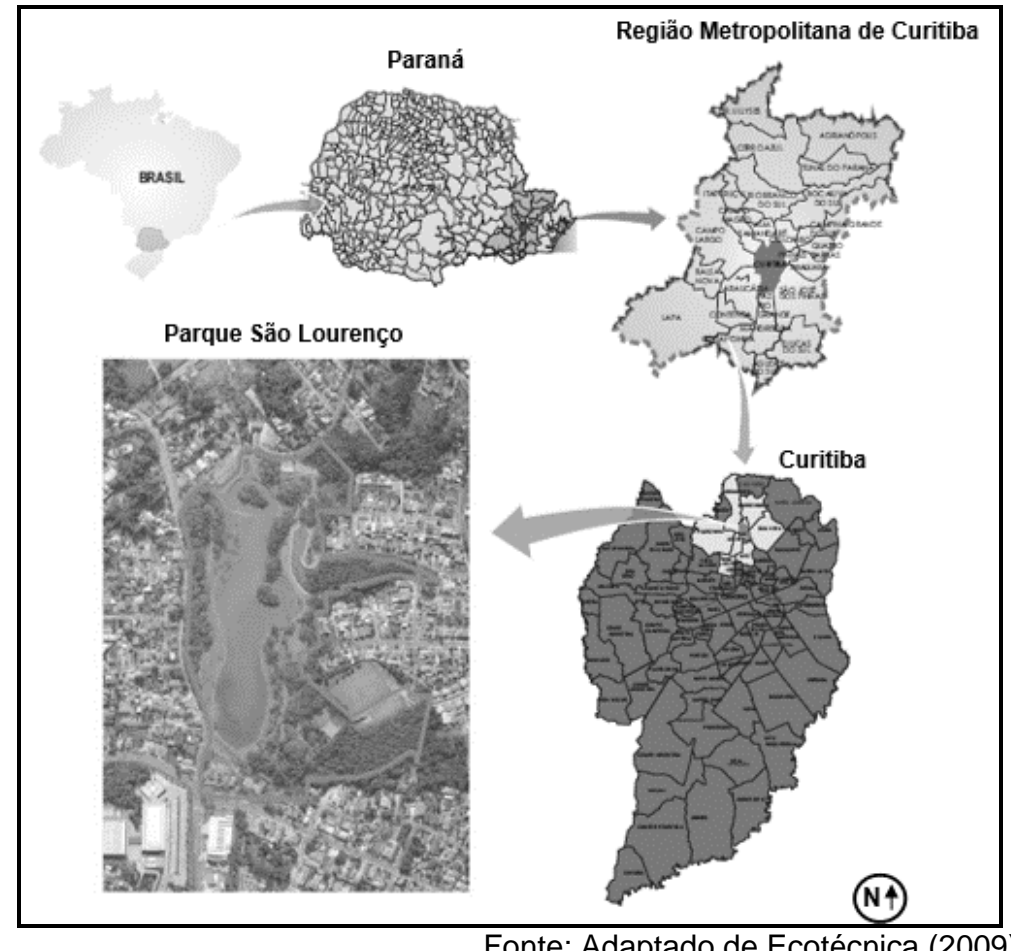

Figura 1. Contexto geográfico e localização do Parque São Lourenço

Figure 1. Geographic location of São Lourenço Park 
O Parque São Lourenço foi inaugurado em 1972 e se deu após uma enchente do rio Belém, em 1970, a qual provocou o rompimento da represa de São Lourenço, paralisando o curtume e a fábrica de cola que funcionavam no local (BIONDI; MULLER, 2013). Desta forma, entende-se que o parque foi idealizado com o intuito de prover água para a cidade e combater enchentes no meio urbano. Além disso, o parque tem por finalidade satisfazer três principais necessidades da população: recreação, educação ambiental e espaço aberto para atividades (ECOTÉCNICA, 2009).

\section{Metodologia}

A coleta de dados se deu por meio de questionário semiestruturado (Figura 2) adaptado de Souza (2010) com os frequentadores do Parque São Lourenço. As pessoas foram entrevistadas entre os dias 12 a 18 de setembro de 2016, no decorrer de uma semana, e foram escolhidas aleatoriamente, sendo que os pesquisadores percorreram toda a extensão do parque e conversaram com frequentadores praticando caminhada, corrida, contemplação da paisagem, ou qualquer outra atividade de uso do parque, sem restrições. Também não houve restrições de gênero, idade e nem classe social.

Para o cálculo de determinação do tamanho da amostra, utilizou-se metodologia de Triola (1999) com base em uma população infinita heterogênea, com nível de confiança a 95\% e erro amostral máximo aceitável de 10\%, totalizando assim em 97 entrevistas, no entanto foram entrevistadas 128 pessoas.

$\mathrm{Na}$ primeira parte do questionário constaram perguntas referentes ao perfil dos entrevistados - região de residência, gênero, faixa etária, renda aproximada, nível de instrução e ocupação profissional. Na segunda parte do questionário as perguntas foram relacionadas aos hábitos de utilização, com perguntas referentes ao meio de locomoção até o parque (veículo coletivo, individual, bicicleta, ou a pé), período do dia que mais utiliza, frequência de uso (semanal, mensal, anual, entre outras) e motivos de utilização do parque. A terceira parte do questionário envolveu perguntas sobre percepção, incluindo o quanto o indivíduo considera o parque importante para si ou para a cidade de forma geral, e solicitado que o entrevistado descrevesse três motivos para esta resposta. Adicionalmente, foi pedido que o entrevistado escolhesse dentre três funções principais do parque - estética, ecológica e social - qual ele considerava predominante. Em seguida, foi perguntado se o indivíduo tinha conhecimento da função principal do parque (que é a de prevenção de enchentes), se gostava do estilo paisagístico do parque e se tinha sugestões de melhoria no paisagismo. Por fim, foi perguntado se o frequentador tinha sugestões ou reclamações em relação à infraestrutura, se utiliza outro parque e se tem motivos para não visitar o parque em estudo. 


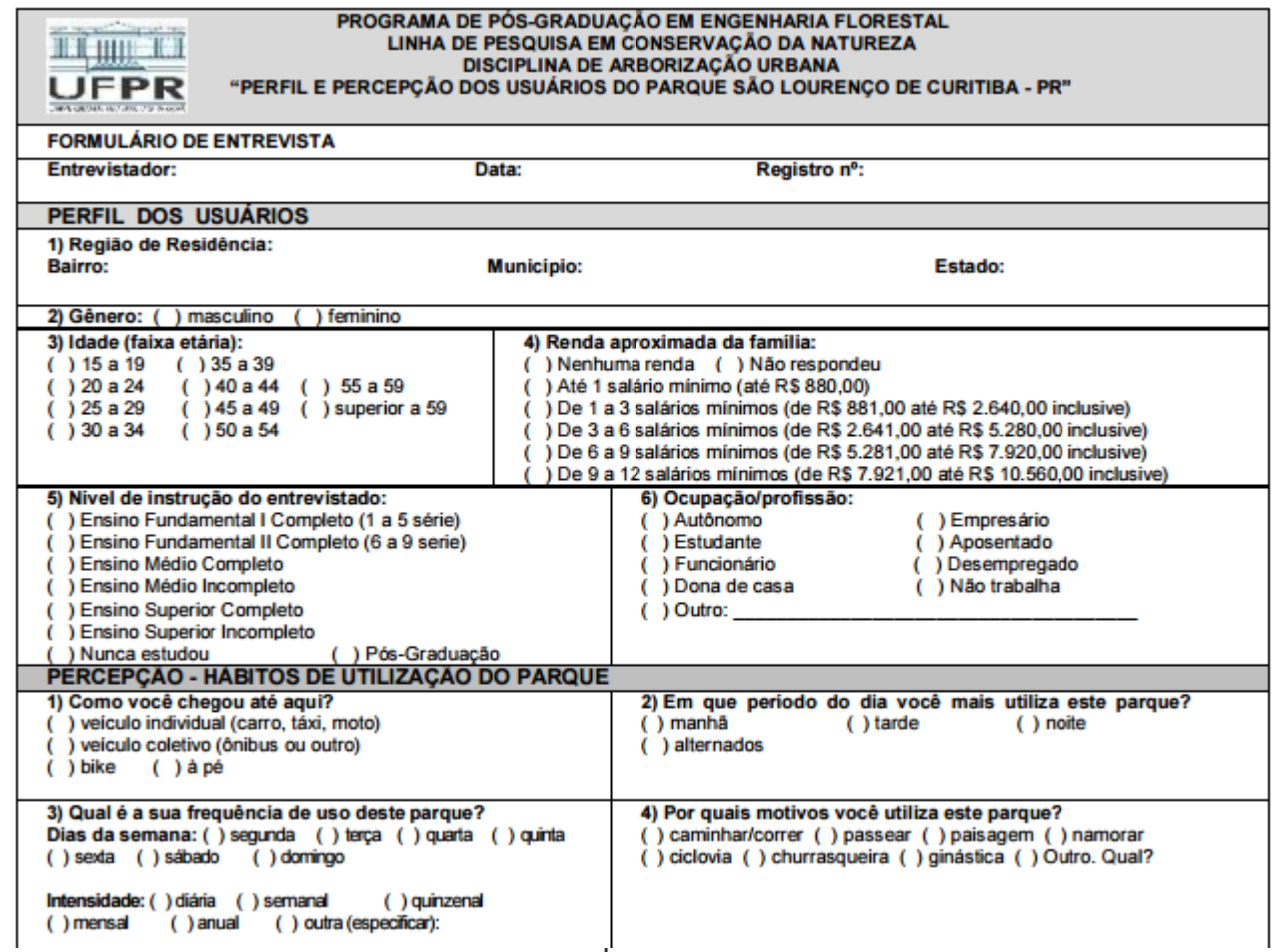

\begin{tabular}{|c|c|}
\hline \multicolumn{2}{|l|}{ PERCEPÇĀO - FUNÇŌES DO PARQUE } \\
\hline $\begin{array}{l}\text { 1) Quanto vocé acha que este parque é importante? } \\
\text { () muito ( ) médio ( ) pouco } \\
\text { () nâo considera importante } \\
\text { Por que? Cite até TRÉS motivos: }\end{array}$ & $\begin{array}{l}\text { 2) Em relação à função deste parque, qual você considera } \\
\text { predominante? } \\
\text { ( ) funçẫo estética ( ) funçăo ecológica ( ) função social } \\
\text { ( ) nenhuma ( ) nấo sabe }\end{array}$ \\
\hline $\begin{array}{l}\text { 3) Você sabia que o parque foi criado com a finalidade de } \\
\text { regular enchentes? } \\
\text { ( ) sim ( ) não }\end{array}$ & $\begin{array}{l}\text { 4) Vocé gosta do estilo paisagistico do parque? } \\
\text { ( ) } \operatorname{sim}(\text { ( ) năo ( ) tanto faz }\end{array}$ \\
\hline 5) O que você melhoraria no paisagismo do parque? & $\begin{array}{l}\text { 6) Sugestões de melhorias em relação à infraestrutura do Parque } \\
\text { São Lourenço: } \\
\text { ( ) acessos são adequados? ( ) segurança ( ) iluminaçāa } \\
\text { ( ) banheiros ( ) sujeira ( ) estacionamento ( ) barulho } \\
\text { ( ) Outro. Qual? }\end{array}$ \\
\hline Observaçōes gerais: & \\
\hline
\end{tabular}

Fonte: Adaptado de Souza (2010).

Figura 2. Questionário semiestruturado aplicado aos frequentadores do Parque São Lourenço Figure 2. Semi structured questionnaire applied to visitors of São Lourenço Park

Os dados provenientes das entrevistas foram processados por meio do software Microsoft Excel 2016, e classificados pelo QGIS 2.18 para análise de influência. 


\section{RESULTADOS E DISCUSSÃO}

\section{Perfil socioeconômico}

Foram entrevistadas 128 pessoas, no decorrer de uma semana, dos dias 12 a 18 de setembro de 2016. Destas, 50,8\% corresponderam ao gênero masculino e 49,2\% ao gênero feminino. Boa parte dos entrevistados $(50,7 \%)$ possui faixa etária distribuída entre 20 a 39 anos e mais da metade dos entrevistados $(59,3 \%)$ possui renda de um a seis salários mínimos. 0 nível de escolaridade distribuiu-se principalmente entre Ensino Superior Completo e PósGraduação $(39,4 \%)$ e Ensino Médio Completo (25\%). E considerando a ocupação profissional, a maioria dos entrevistados se declaram "funcionários" $(35,9 \%)$, "estudantes" $(21,1 \%)$, e "trabalhadores autônomos" (18\%).

A análise de perfis socioeconômicos em estudos da percepção ambiental é importante uma vez que permite conhecer os indivíduos envolvidos, facilitando a realização de ações de sensibilização e educação ambiental sobre determinados assuntos específicos com base local (MONTEIRO et al., 2013).

Foi possível inferir o alcance do parque em 34 localidades, tanto em bairros da cidade quanto na Região Metropolitana de Curitiba (RMC), e também de outras cidades. Na Figura 3 foram destacados os principais locais de residência dos frequentadores do Parque São Lourenço considerando o município de Curitiba.

Os frequentadores que visitaram o parque no período das entrevistas vieram de diversas regionais do município de Curitiba. As mais citadas foram a Regional Boa Vista (que no estudo compreendeu os bairros: Abranches, Pilarzinho, São Lourenço, Barreirinha, Bacacheri, Boa Vista e Taboão, totalizando 42,2\%) e Regional Matriz (que no estudo compreendeu os bairros: Centro, Cabral, Bigorrilho, Ahú, Centro Cívico, Bom Retiro, Hugo Lange, Jardim Social, Juvevê, Mercês e São Francisco, totalizando 36,7\%), ambas somando $78,9 \%$.

Por outro lado, a soma dos bairros que originaram menor visitação foi de $7,1 \%$ compreendendo as seguintes regionais: Regional Cajuru (que no estudo compreendeu os bairros: Cajuru e Uberaba, totalizando 3,1\%), Santa Felicidade (compreendendo o bairro Vista Alegre $(1,6 \%)$ ), Boqueirão (que no estudo abrangeu o bairro Hauer $(0,8 \%)$ ), Pinheirinho (que no estudo abrangeu o bairro Pinheirinho $(0,8 \%)$ ) e Tatuquara (que no estudo abrangeu o bairro Tatuquara $(0,8 \%))$. A grande diferença percebida em relação às regionais Boa Vista e Matriz com as demais regionais e localidades deve-se ao fato de que o referido parque se situa na regional Boa Vista e muito próximo à regional Matriz, proporcionando assim, maior visitação por seus moradores e vizinhos. Já as localidades da RMC e de outras cidades totalizaram 14\% sendo elas: Almirante Tamandaré, Araucária, Pinhais, Piraquara, São José dos Pinhais e 
Colombo. O que corrobora com os resultados encontrados em estudo semelhante feito por Hildebrand, Graça e Milano (2001), onde o raio de influência médio das áreas verdes foi de 4,0 $\mathrm{km}$, evidenciando a maior frequência dos visitantes oriundos de bairros que circundam 0 parque, ainda que haja a presença de frequentadores oriundos de bairros mais afastados, demonstrando que as áreas verdes urbanas são importantes não somente para os moradores ao redor das mesmas como também para a população da cidade e para o turismo local.

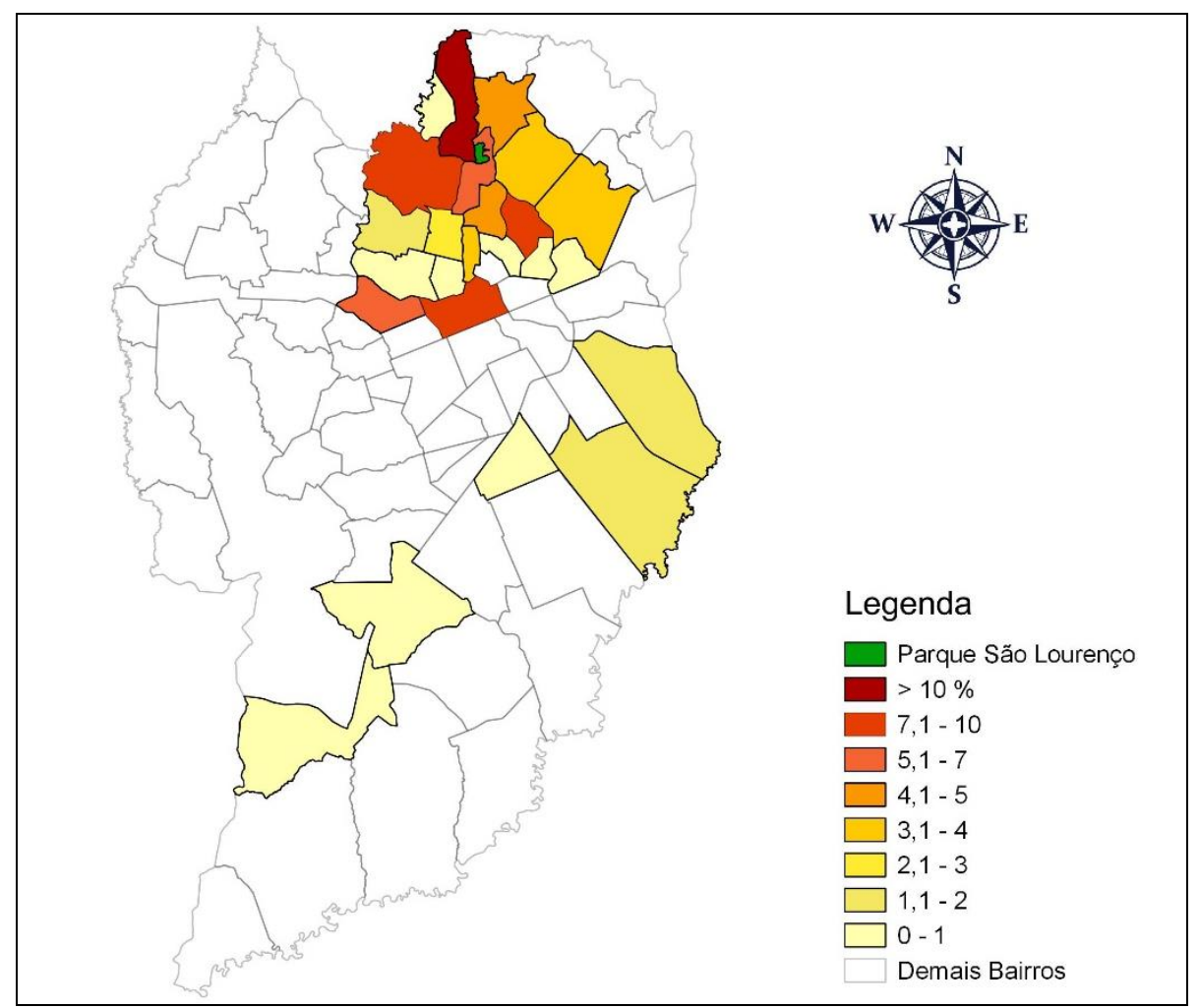

Nota: >10\%: Abranches; 7,1 - 10\%: Pilarzinho, Centro e Cabral; 5,1 - 7\%: São Lourenço e Bigorrilho; 4,1 - 5\%: Ahú e Barreirinha; 3,1 - 4\%: Centro Cívico, Bacacheri e Boa Vista; 2,1 - 3\%: Bom Retiro; 1,1 - 2\%: Cajuru, Uberaba e Vista Alegre; 0 - 1\%: Hauer, Hugo Lange, Jardim Social, Juvevê, Mercês, Pinheirinho, São Francisco, Taboão e Tatuquara

Figura 3. Principais bairros de residência dos frequentadores do Parque São Lourenço em Curitiba - PR Figure 3. Main districts inhabited by users of São Lourenço Park, in Curitiba

\section{Hábitos de utilização do parque}

Quanto ao modo como chegaram até o parque, $42 \%$ dos frequentadores se locomoveu até o São Lourenço utilizando veículo individual, seja ele carro ou moto. O segundo meio de transporte mais utilizado foi o ônibus, por $26 \%$ das pessoas, enquanto $18 \%$ chegaram até o parque a pé e $14 \%$ chegaram de bicicleta.

Quanto à frequência de visitação em relação aos dias da semana, $41 \%$ dos entrevistados visitam o parque três vezes na semana, $23 \%$ visitam duas vezes na semana, $12 \%$ visitam uma vez na semana, para $21 \%$ dos entrevistados a frequência é indiferente, e o 
restante soma 3\%, sendo estes quatro vezes na semana e cinco vezes na semana. E quanto à intensidade de visitação, $57 \%$ dos entrevistados declaram visitar o parque pelo menos semanalmente, $25 \%$ mensalmente, $10 \%$ diariamente, e os outros $8 \%$ somam semestral, quinzenal e anualmente.

Em relação aos períodos do dia em que fazem uso do parque, dos entrevistados, nenhuma pessoa respondeu que vai ao parque à noite, sendo que $65 \%$ utiliza o São Lourenço no horário da tarde, e o restante pela manhã.

A falta de uso do parque à noite pode estar diretamente relacionada com o seguinte resultado: em questão aberta, foi perguntado se o frequentador tem qualquer motivo para não visitar o parque. Dentre aqueles que declararam ter motivos, $35 \%$ alegou que o motivo seria "segurança", e outros 35\% responderam "segurança à noite", totalizando $70 \%$. O restante dos entrevistados apontou diversos outros motivos como: excesso de pessoas, som alto, poluição da água e acidentes entre ciclistas e pedestres.

Durante pesquisa realizada em 2008, para o Plano de Manejo do Parque, a consultoria Ecotécnica (2009) constatou que os frequentadores apontavam "segurança" e "poluição do lago" como os dois maiores motivos para não visitar o parque. Com resultado similar ao deste estudo, grande parte dos entrevistados (81\%) em 2008 também não frequentava o parque no período da noite sendo que a preocupação com a segurança também era o principal motivo da restrição de visitas naquela época. Wendel, Zarger e Mihelcic (2012) em estudo realizado na cidade de Santa Cruz na Bolívia também concluíram que a segurança era uma preocupação recorrente da maioria dos entrevistados, corroborando assim com os resultados deste estudo.

Ao perguntar aos frequentadores sobre os principais motivos pelos quais frequentam o Parque São Lourenço, obteve-se uma extensa gama de respostas que posteriormente foram agrupadas em categorias na Tabela 1.

Tabela 1. Categorização das respostas mais citadas referentes aos motivos que levam os frequentadores a frequentar o Parque São Lourenço

Table 1. Categorization of the most cited answers regarding the reasons that lead users to attend São Lourenço Park

\begin{tabular}{ccc}
\hline Categoria & Respostas mais citadas & № de respostas (\%) \\
\hline Lazer e recreação & $\begin{array}{c}\text { caminhar, passear, levar crianças, namorar, utilizar } \\
\text { churrasqueiras } \\
\text { Saúde e bem-estar } \\
\text { atividade física, ginástica, exercícios físicos, saúde, } \\
\text { tranquilidade, refletir, descansar, arejar, calma, } \\
\text { sossego, meditar, relaxar, silêncio }\end{array}$ & 49,5 \\
Paisagem & admirar a paisagem & 16,5 \\
Ciclovia & andar de bicicleta, atalhar caminho & 15,6 \\
Proximidade & único parque da região, acessível, boa localização & 12,8 \\
Trabalho & atalho para o trabalho, trabalho no próprio parque & 3,8 \\
\hline
\end{tabular}


Analisando a Tabela 1 percebe-se que as atividades de lazer e recreação se configuram como a principal motivação da visitação ao parque, o que se deve ao fato das pessoas estarem constantemente sob estresse ou cansadas de sua rotina de trabalho, encontrando no parque, um ambiente adequado para relaxar e curtir um pouco mais a vida.

Ferreira (2007) destaca que a rotina cansativa imposta pela vida urbana pode ser atenuada por atividades realizadas nos parques, como caminhadas, passeios e brincadeiras, além da possibilidade de convivência entre os moradores nas cidades nesses espaços, e esse benefício ligado ao lazer está também associado à função psicológica de aliviar o estresse. Ou seja, os parques podem auxiliar na promoção da saúde e bem estar, que foi a segunda categoria mais citada como motivo de visitação, além de possibilitar o aumento do nível de atividade física dos ativos. Segundo Londe e Mendes (2014), a realização de atividades físicas em espaços, como as áreas verdes, pode trazer benefícios fisiológicos imediatos e em longo prazo aos praticantes. Barton e Pretty (2010) determinaram por meio de um estudo de metaanálise, que apenas cinco minutos de exercício em áreas naturais, é suficiente para trazer melhorias à saúde mental (humor e autoestima) dos indivíduos, sugerindo benefícios imediatos. Tais evidências implicam ainda, segundo os mesmos autores, que as pessoas sedentárias e/ou com problemas de natureza psíquica, teriam benefícios na saúde mental se comprometendo a exercícios de curta duração, em espaços verdes acessíveis.

Estes apontamentos revelam, portanto, os benefícios que as áreas verdes públicas urbanas podem proporcionar à saúde e ao bem-estar da população. Desse modo, a construção de novas áreas verdes, a revitalização das existentes, ou mesmo, a conservação da vegetação presente no espaço urbano, deve ser encarada pelos gestores municipais como benefício futuro a toda população citadina (PEREHOUSKEI; DE ANGELIS, 2012).

A beleza da paisagem, a ciclovia, a proximidade do parque ao trabalho e às pessoas parecem ser também determinantes para a adesão e manutenção de frequentadores assíduos. Com relação à proximidade ao parque, se volta ao fato de ser mais cômodo para o deslocamento do frequentador já que o parque se localiza próximo ao centro da cidade, favorecendo a acessibilidade, especialmente por transporte coletivo.

\section{Percepção paisagística e funções do parque}

Quando perguntados sobre o nível de importância atribuído ao Parque São Lourenço, 93\% dos entrevistados o consideraram como sendo muito importante e $7 \%$ atribuíram a ele média importância. A média importância se deu em razão dos parques não serem prioridade, já que outras áreas merecem mais atenção e também devido a sua localização, pois alguns frequentadores preferem parques afastados da cidade, pois são menos barulhentos. Aos 
entrevistados que atribuíram ao parque alto grau de importância, obteve-se uma gama extensa de respostas evidenciando os motivos pelos quais o consideram muito importante e os mesmos foram agrupados em categorias na Tabela 2.

Priego, Breuste e Rojas (2008) encontraram em estudo comparativo de frequentadores de parques urbanos no Chile, Alemanha e Espanha que, independentemente do local onde residiam, a população declara em geral que parques são muito importantes para suas vidas. Neste mesmo estudo os autores encontraram que em média $90 \%$ dos chilenos, alemães e espanhóis declararam que parques de seu dia-a-dia são fundamentais para sua qualidade de vida, e que o contato com a natureza é fundamental para aliviar a tensão da vida moderna, além de ser um espaço para convívio com a comunidade.

Tabela 2. Categorização das respostas mais citadas referentes aos motivos do grau de importância alto atribuído pelos frequentadores ao Parque São Lourenço

Table 2. Categorization of the most cited answers regarding the reasons for the high degree of importance attributed by users to São Lourenço Park

\begin{tabular}{|c|c|c|}
\hline Categoria & Respostas mais citadas & № de respostas (\%) \\
\hline Lazer e recreação & $\begin{array}{l}\text { esporte, férias, passear, levar crianças, relaxar, } \\
\text { paz, meditar, descansar, arejar, tranquilidade, } \\
\text { sentar, pensar, passatempo }\end{array}$ & 27,0 \\
\hline Natureza & $\begin{array}{l}\text { acesso a natureza, contato com natureza, ar puro, } \\
\text { clima, valor do espaço verde, meio ambiente }\end{array}$ & 23,7 \\
\hline Saúde e bem-estar & $\begin{array}{c}\text { atividades físicas, saúde, vida saudável, qualidade } \\
\text { de vida }\end{array}$ & 15,8 \\
\hline Preservação & $\begin{array}{c}\text { preservação/ conservação da natureza, fauna e } \\
\text { água }\end{array}$ & 8,6 \\
\hline Proximidade & único parque na região, acessível, boa localização & 6,6 \\
\hline Paisagem & $\begin{array}{l}\text { admirar a paisagem, beleza, limpeza, lugar para } \\
\text { desfrutar, parques são símbolos de Curitiba }\end{array}$ & 5,3 \\
\hline Confraternização & sociedade, união de famílias, ficar com amigos & 4,6 \\
\hline Acesso gratuito & local de qualidade gratuito & 3,2 \\
\hline Ciclovia & andar de bicicleta, atalhar caminho & 1,3 \\
\hline Turismo & primeira vez no parque, conhecer o parque & 1,3 \\
\hline Regulação de enchentes & importante para conter enchentes & 1,3 \\
\hline Segurança & seguro, não é perigoso & 1,3 \\
\hline
\end{tabular}

Percebe-se que as categorias de "lazer e recreação", "natureza" e "saúde e bem estar" se configuram como motivos que dão maior importância ao parque, seguidas de outras, conforme Tabela 2. Com base nisso, percebe-se que as pessoas estão cada vez mais em busca de qualidade de vida, e dão a entender que uma forma de encontrá-la é no parque.

A finalidade dos espaços verdes livres é a plena expansão das funções de lazer e recreação, e principalmente uma forma de lazer e diversão acessível a todas as classes sociais, atendendo às necessidades da população de manter contato com a natureza (PAIVA, 2008). Neste contexto, Souza (2010) afirma que o potencial do parque urbano, como área 
verde, é inquestionável, a começar pelos serviços ambientais que presta ao seu entorno imediato. $\mathrm{O}$ autor assegura que esses serviços são relativos à manutenção da biodiversidade local e regional, à drenagem de águas pluviais, à regulação microclimática, ao equilíbrio e à qualidade do ar, sem contar com a rica possibilidade de servir de local a atividades de educação ambiental. Sousa e Machado (2007) apontam que esses serviços ambientais ainda carecem de medidas, mas, sem dúvida, são prestados pelas áreas verdes.

Em relação ao estilo paisagístico do parque, 95,4\% dos entrevistados responderam que gostam do estilo, 2,3\% que não gostam e os outros $2,3 \%$ que tanto faz, é indiferente. As sugestões de melhorias no paisagismo propostas pelos frequentadores foram de plantar flores e árvores frutíferas e nativas, despoluir o rio Belém e fazer a drenagem das áreas alagadas.

Segundo Paiva (2008) o paisagismo se torna um fator importante para deixar os parques mais belos e mais agradáveis para o deleite e o desfrute de seus visitantes, além de acrescentar um valor ecológico-paisagístico às áreas alteradas. Na visão de Vieira (2007), a arquitetura paisagística contemporânea está calcada sobre valores relacionados à proteção e à manutenção do meio ambiente. Desta forma, o paisagismo tem papel conciliador proporcionando melhorias sociais e ambientais às cidades, atendendo à emergente necessidade que ora se aponta (SHAMS; LIMA; ZANFORLIN, 2010).

Segundo Bargos e Matias (2011), a manutenção das áreas verdes urbanas sempre foi justificada pelo seu potencial em propiciar qualidade ambiental à população. Os mesmos autores relatam que ela interfere diretamente na qualidade de vida dos seres por meio das funções sociais, ecológicas e estéticas que elas exercem para amenização das consequências negativas da urbanização. Dentre as principais funções do parque, a que foi considerada predominante pelos entrevistados foi a ecológica (46,9\%), seguida da social $(38,3 \%)$ e da estética $(14,8 \%)$.

Foi perguntado ainda se o entrevistado tinha conhecimento da finalidade do parque na prevenção de enchentes, sendo que as respostas foram equilibradas entre os entrevistados, com ligeira predominância para a resposta "Sim", com 58\%, o que configura uma importante informação, visto que a população tem certo conhecimento de que a criação de parques faz com que o problema de enchentes seja reduzido, uma vez que aumenta a capacidade de infiltração das regiões próximas aos rios, além de criar melhorias quanto ao paisagismo urbano.

Em relação à infraestrutura do parque, as maiores reclamações e anseios dos frequentadores estão relacionados principalmente à construção de mais um banheiro e limpeza do já existente $(22,4 \%)$, mais segurança e policiamento no parque $(18,4 \%)$, iluminação à noite $(12,0 \%)$, maior quantidade de bancos $(7,9 \%)$, construção de um quiosque para alimentação $(7,9 \%)$, implantação de bebedouros $(6,6 \%)$, construção de ciclovia no lado oeste do parque $(6,6 \%)$, ampliação do estacionamento $(3,9 \%)$, mais lixeiras distribuídas pelo parque $(3,9 \%)$, 
mais churrasqueiras (2,6\%), melhorias na comunicação visual (placas) e orientações aos frequentadores $(2,6 \%)$, construção de mais uma academia $(2,6 \%)$ e de um parque infantil com maior diversidade de brinquedos (2,6\%). Com uma infraestrutura adequada será possível garantir a satisfação dos frequentadores. Segundo Souza (2010), quando um parque é bem conservado e possui infraestrutura adequada, melhores condições serão proporcionadas para que haja melhoria de qualidade de vida da população.

Quando perguntado se utilizam outras áreas verdes, 69,5\% responderam que "sim" sendo que o restante utiliza apenas o Parque São Lourenço. As áreas verdes mais utilizadas pelos entrevistados foram o Parque Barigui $(29,4 \%)$, seguido do Parque Tingui $(12,6 \%)$, Bosque João Paulo II (11,8\%), Passeio Público (9,8\%), Jardim Botânico (9,1\%), Parque Tanguá (7\%), Parque Bacacheri (5,6\%), Parque da Barreirinha $(3,5 \%)$, Bosque do Alemão (3,5\%), Bosque Boa Vista (2,1\%) e Parque do Pilarzinho (1,4\%). Além disso, foram obtidas as respostas: "variado" $(2,1 \%)$, ou seja, independia o parque e "todas" $(2,1 \%)$ onde o frequentador declarou que visitava todas as áreas verdes da cidade.

Por fim, é importante salientar que a manutenção das áreas verdes é extremamente importante para que estas possam cumprir plenamente suas funções (SANTOS; HERMANO, 2015).

\section{CONCLUSÕES}

O Parque São Lourenço é frequentado principalmente por jovens e adultos, e por pessoas que moram no entorno ou na região do parque. No entanto o alto percentual do total de bairros participantes da pesquisa pode ser indicativo da carência de parques em determinadas regiões de Curitiba.

Apesar da boa aceitação do parque por parte dos entrevistados, ainda são necessários alguns ajustes, como incrementação do paisagismo com árvores nativas e frutíferas, despoluição do rio Belém, construção e manutenção de banheiros, mais segurança e policiamento, melhor iluminação e maior quantidade de bancos, o que ocasionará em um maior conforto e segurança para os frequentadores no parque.

Por fim percebeu-se a necessidade de implantação de programas de educação ambiental no local de estudo, já que os frequentadores não possuem uma visão clara em relação às funções que um parque pode desempenhar. 


\section{REFERÊNCIAS}

BARGOS, D. C.; MATIAS, L. F. Áreas verdes urbanas: um estudo de revisão e proposta conceitual. Revista da Sociedade Brasileira de Arborização Urbana, Piracicaba, v. 6, n. 3, p. 172-188, 2011.

BARTON, J.; PRETTY, J. What is the best dose of nature and green exercise for improving mental health? A multi-study analysis. Environmental Science and Technology, Berkeley, v. 44, n. 10, p. 3947-3955, 2010.

BIONDI, D.; MULLER, E. Espécies arbóreas invasoras no paisagismo dos parques urbanos de Curitiba, PR. FLORESTA, Curitiba, v. 43, n. 1, p. 69-82, 2013.

ECOTÉCNICA. Plano de Manejo do Parque Natural Municipal São Lourenço. Curitiba, 2009. Disponível em: <http://www.curitiba.pr.gov.br/conteudo/plano-de-manejo-smma/322> Acesso em: 10 out. 2016.

FERREIRA, L. I. E. P. Parque urbano. Paisagem Ambiente: ensaios, São Paulo, v. 1, n. 23, p. 20-33, 2007.

HERZOG, C. P.; ROSA, L. Z. Infraestrutura verde: sustentabilidade e resiliência para a paisagem urbana. Revista LabVerde, São Paulo, v. 1, n. 1, p. 92-115, 2010.

HILDEBRAND, E.; GRAÇA, L. R.; MILANO, M. S. Distância de deslocamento dos visitantes dos parques urbanos em Curitiba - PR. Floresta e Ambiente, Seropédica, v. 8, n. 1, p. 76-83, 2001.

LEICHENKO, R. M.; SOLECKI, W. D. Consumption, inequity, and environmental justice: The making of new metropolitan landscapes in developing countries. Society \& Natural Resources, United Kingdom, v. 21, n. 7, p. 611-624, 2008.

LONDE, P. R.; MENDES, P. C. A influência das áreas verdes na qualidade de vida urbana. Revista Brasileira de Geografia Médica e da Saúde, Hygeia, v. 10, n. 18, p. 264-272, 2014.

MATSUOKA, R. H.; KAPLAN, R. People needs in the urban landscape: Analysis of Landscape and Urban Planning contributions. Landscape and Urban Planning, Wageningen, v. 84, n. 1, p. 7-19, 2008.

MITCHELL, R.; POPHAM, F. Effect of exposure to natural environment on health inequalities: An observational population study.The Lancet, United Kingdom, v. 372, n. 9650, p. 1655-1660, 2008.

MONTEIRO, M. M. G.; TETTO, A. F.; BIONDI, D.; SILVA, R. R. S. Percepção dos usuários em relação à arborização da Avenida Cândido de Abreu - Curitiba - PR. Revista da Sociedade Brasileira de Arborização Urbana, Piracicaba, v. 8, n. 2, p. 20-34, 2013.

NASIR, R. A.; AHMAD, S. S.; AHMED, A. Z. The relationship of physical activity and human comfort in urban park. Asian Journal of Behavioral Studies, United Kingdom, v. 1, n. 2, p. 3648, 2016.

PAIVA, P. D. de O. Paisagismo: conceitos e aplicações. Lavras: Editora UFLA, 2008. 608p.

PEREHOUSKEI, N. A.; DE ANGELIS, B. L. D. Áreas verdes e saúde: paradigmas e experiências. Diálogos \& Saberes, Mandaguari, v. 8, n. 1, p. 55-77, 2012. 
PRIEGO, C.; BREUSTE, J. H.; ROJAS, J. Perception and value of nature in urban landscapes: a comparative analysis of cities in Germany, Chile and Spain.Landscape Online, Eberswalde, v. 7, n. 1, p. 1-22, 2008.

SANTOS, W. R.; HERMANO, V. M. As praças de Janaúba: diagnóstico socioambiental e reflexões sobre a área verde urbana. Revista Multitexto, Montes Claros, v. 3, n. 1, p. 47-54, 2015.

SHAMS, J. C. A.; LIMA, A. M. L. P.; ZANFORLIN, C. Serviços de paisagismo no estado de São Paulo. Revista da Sociedade Brasileira de Arborização Urbana, Piracicaba, v. 5, n. 4, p. 5780, 2010.

SILVA, R. R. S.; BIONDI, D. ; BARDELLI-DA-SILVA, M. Y. ; SILVA, D. Avaliação da qualidade e diversidade da paisagem do Parque São Lourenço para fins recreativos e turísticos. Revista da Sociedade Brasileira de Arborização Urbana,Piracicaba, v. 7, n. 4, p. 53-68, 2012.

SOUSA, M. T. R. de; MACHADO, R. Os parques urbanos e a cidade sob a abordagem do turismo e do planejamento dos transportes. Gaia Scientia, João Pessoa, v. 1, n. 2, p.169-180, 2007.

SOUZA, P. C. A de. Funções sociais e ambientais de parque urbano instituído como unidade de conservação: percepção dos frequentadores do Parque Natural Municipal Barigui em Curitiba, Paraná. Curitiba, 2010. 146f. Dissertação (Pós-Graduação em Gestão Urbana) - Pontifícia Universidade Católica do Paraná, Curitiba, 2010.

TRIOLA, M. F. Introdução à Estatística. 7. ed. Rio de Janeiro: LTC, 1999.

VIEIRA, M. E. M. O jardim e a paisagem: espaço, arte, lugar. São Paulo: Annablume, 2007. $254 p$.

WENDEL, H. E. W.; ZARGER, R. K.; MIHELCIC, J. R. Accessibility and usability: Green space preferences, perceptions, and barriers in a rapidly urbanizing city in Latin America. Landscape and Urban Planning, Wageningen, v. 107, n. 3, p. 272-282, 2012.

WILLEMSE, L. Community Neighbourhood Park (CNP) Use in Cape Town's Townships. Urban Forum, Stellenbosch, v. 23, n. 2, p. 221-231, 2012. 